\title{
Dual Band Microstrip Antenna using Shorted Metallic Patches
}

\author{
Manisha Gupta \\ Dept. ECE, ABES Engineering College Ghaziabad \\ UP, India
}

\author{
Rakesh Kumar \\ Dept. ECE, ABES Engineering College Ghaziabad \\ UP, India
}

\begin{abstract}
A compact monopole antenna having dual band characteristics using shorted metallic patches is presented. To get impedance matching for the SMA conductor, the antenna is fed up by probe feeding technique. The shorted metallic patches are made by square patches which are connected to the ground plane by the shorting pins. SMPs are used to improve the gain of the antenna. The dimensions and position of the SMPs and the position and dimension of the slot with respect to the patch are important and studied in this paper.
\end{abstract}

\section{Keywords}

Dual band Notches; Shorted Metallic patches; Probe feeding;

\section{INTRODUCTION}

With the increase of application in wireless communications, dual-band microstrip patch antenna have become highly desirable due to their many advantages such as light weight, thin profile configuration, stable radiation characteristics and easy to fabricate as well as multitasking capability. In this paper, SMPs are used to increase the gain. Generally there are many methods are used to increase the gain such as using thick substrates, parasitic elements and stacked configuration etc. But here gain is increased by using SMPs around the patch antenna. Dual band is generated by a rectangular slot created in the patch. The dimensions and position of the SMPs and the position and dimension of the slot with respect to the patch are important and studied in this paper. The dimension and position of the probe feeding are also important to generate $50 \Omega$ resistance.

There are many different type of shape of slits or slots are used to generate the dual band functions which have been discussed in [1-10]. In [1] different shapes of slots such as T-shaped and W-shaped are used to obtain the desired multi band notch Characteristics. Many applications having a need of multiband linear and circular polarizations performance within a single antenna [2]. Mostly networks such as WLAN used circular polarization $(\mathrm{CP})$ to improve the polarization effectiveness of link budget [3]. Two semicircle on the base edge of the ground plane and two bevel slots on the upper edge [4] and using a half -bowtie radiation patch with staircase shape [5] are also used for the bandwidth enhancement.

Wide Band antennas are also for the rejection of the electromagnetic interfaces with other existing communication systems, such as (3.18-3.66) GHz- Wi-MAX, (5.18-6.22) GHzWLAN, (6.89-9.07) GHz-X bands [6]. Other methods such as inverted $\mathrm{F}$ shape type radiating patch with $\mathrm{L}$ - shape ground having a square on the upper corner [7] and square patch with L and $\mathrm{E}$ shaped slits and ground plane with $\mathrm{V}$-shaped protruded strip [8] are also used to enhance the bandwidth or to get ultrawide bands. A new concept of rectangular filtering dielectric resonator antenna (FDRA) for wide bandwidth and high gain was firstly introduced in [9]. Other wideband antennas with dual or multi notched frequency bands have been shown in [10]-[11] In these designs, by inserting the proper slits in the radiating patch, changing the position of feed line or the ground plane, two or more rejected bands have been obtained.

In this paper, we used a method of SMP to project a monopole antenna with dual-band and linear polarization. The front plane is embedded by many SMPs, to get better gain. Introduction of SMP around the patch antenna causes a shift in its resonant frequency from $5.6 \mathrm{GHzto} 5.78 \mathrm{GHz}$, in addition to a reduction in its $(\mathrm{S} 11=-10 \mathrm{~dB})$ impedance bandwidth

\section{ANTENNA DESIGN}

The simulation of the proposed antenna structure have been done by using finite element method (FEM) software, HFSS. The proposed multifunction monopole antenna is fed by a $50 \Omega$ probe feed line is shown in Fig.1, which is printed on an GML 1032 having dielectric permittivity 3.2 and $\tan \delta=0.014$. The basic structure of antenna is designed by a rectangular radiating patch, a cylindrical probe feed line, and a ground plane. The conducting ground plane is designed on the back side of substrate. The SMPs and the rectangular patch was designed on GML 1032 substrate of size $80 \mathrm{~mm} \times 80 \mathrm{~mm}$. The square shorted patches have $8 \mathrm{~mm} \times 8 \mathrm{~mm}$ side dimensions and the space between the square shorted patches are $0.2 \mathrm{~mm}$. The dimension of the middle patch is $14 \mathrm{~mm} \times 20 \mathrm{~mm}$. The SMPs are connected to the ground by the shorting pins. The centre vias has $0.6 \mathrm{~mm}$ radius. A rectangular slot $(12 \times 1 \mathrm{~mm})$ is cut in the middle patch due to dual band is generated.

In this design, only one resonant mode is excited by changing the feed position along the $\mathrm{x}$ or $\mathrm{y}$ axis, but two different resonant modes (TM01 and TM10 ) can be obtained by placing the feed position in spaces between $\mathrm{x}$ and $\mathrm{y}$ axes (or an asymmetric position), simultaneously.

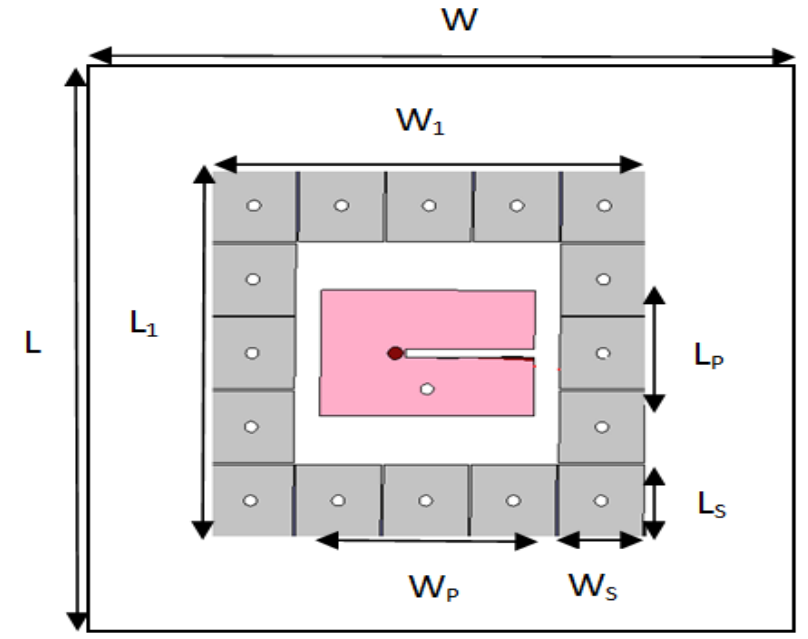




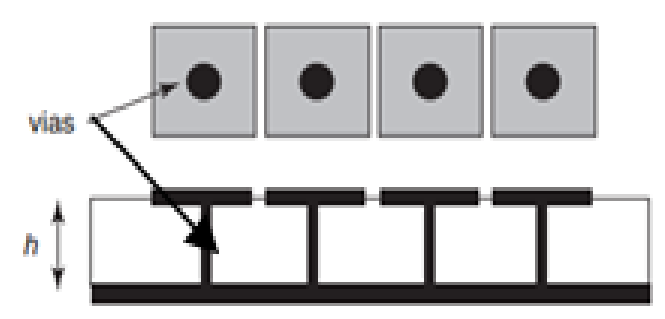

Fig. 1. Geometry of the proposed dual band-notched SMP antenna( front side of the substrate)

The optimum dimensions of the designed antenna are as follows: $\mathrm{W}=80 \mathrm{~mm}, \mathrm{~L}=80 \mathrm{~mm}, \mathrm{WP}=20 \mathrm{~mm}, \mathrm{LP}=14 \mathrm{~mm}, \mathrm{WS}=8 \mathrm{~mm}, \mathrm{LS}=$ $8 \mathrm{~mm}, \mathrm{~L} 1=40.8 \mathrm{~mm}, \mathrm{~W} 1=40.8 \mathrm{~mm}$.

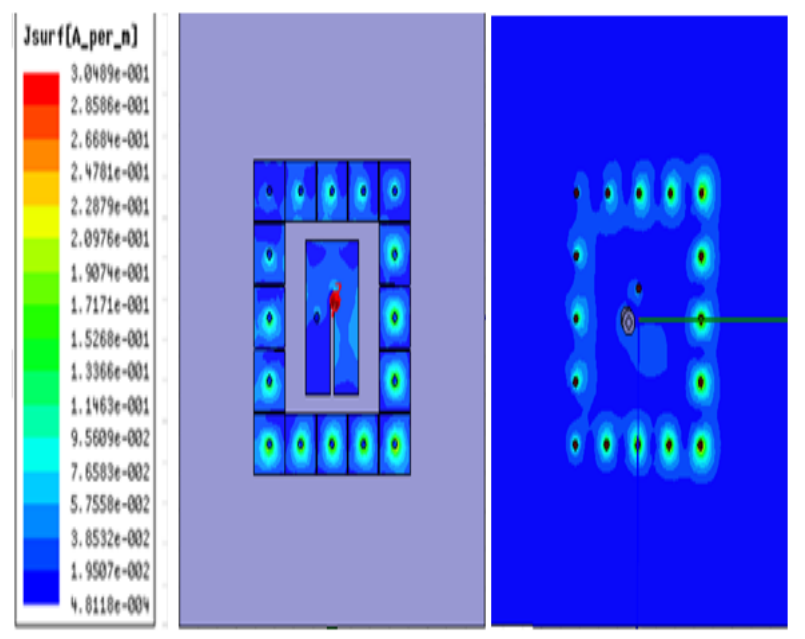

Fig. 2. Surface Current Distribution in the radiating patch and ground plane at $5.6 \mathrm{GHz}$

If the number of SMP ring layer increases then it results the gain to drop from its maximum value obtained by a single layer. The coupling between the SMP elements causes a reduction in the surface current density on the first layer adjacent to the patch antenna by exciting currents on the second layer. However, the radiation by the second layer does not add co-phasally resulting in a reduction of gain. Consequently, with a single ring layer, it was concluded that the individual SMPs act as a parasitic element in this case, which causes an increase in the overall gain.

This increase in the gain is ascribed to an increase in the antenna aperture area by the surrounding SMP ring. This effect is illustrated by the surface current density plot shown in Fig. 2 . The light grey colours display the higher current densities.

\section{RESULT AND DISCUSSION}

The antenna was fabricated on a $1.59 \mathrm{~mm}$ thick GML-1032 substrate with relative dielectric constant of 3.2 and measured using a HFSS analyzer. The return loss of monopole antenna is shown in fig. 3. We get dual bands in which radiate notches frequencies are $3.68 \mathrm{GHz}$ and $3.98 \mathrm{GHz}$, which covers the CBAND applications

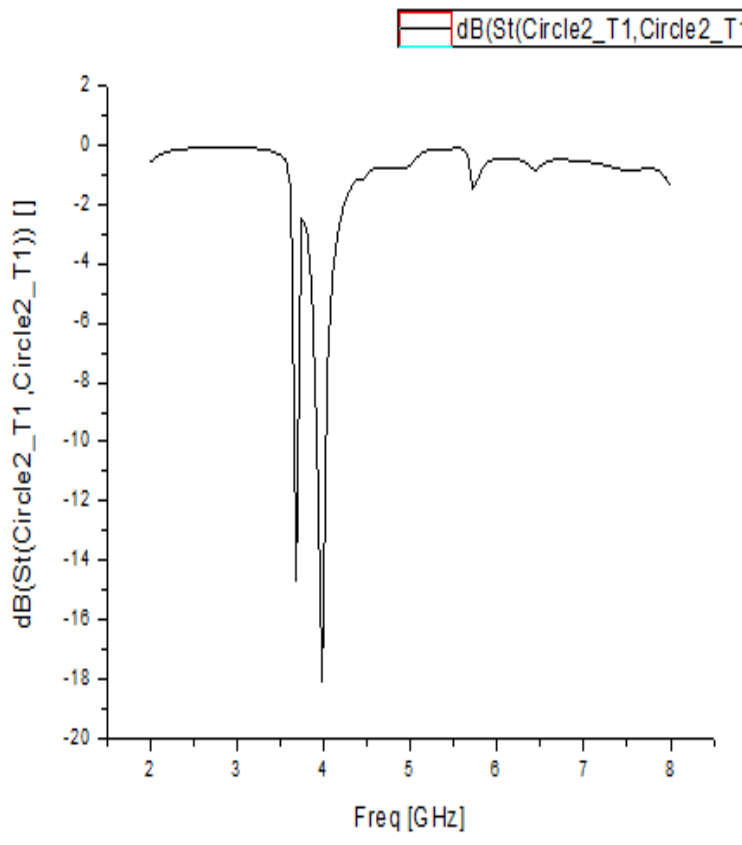

Fig 3. Simulated Return Loss

The simulated gain of the antenna is also presented in fig.4. The approx. gain is $6 \mathrm{~dB}$, which is a good gain. The gain of the dualband SMP antenna is more than the gain of the single band SMP antenna. The comparison of results in different type of SMP antenna is shown in table 1 .

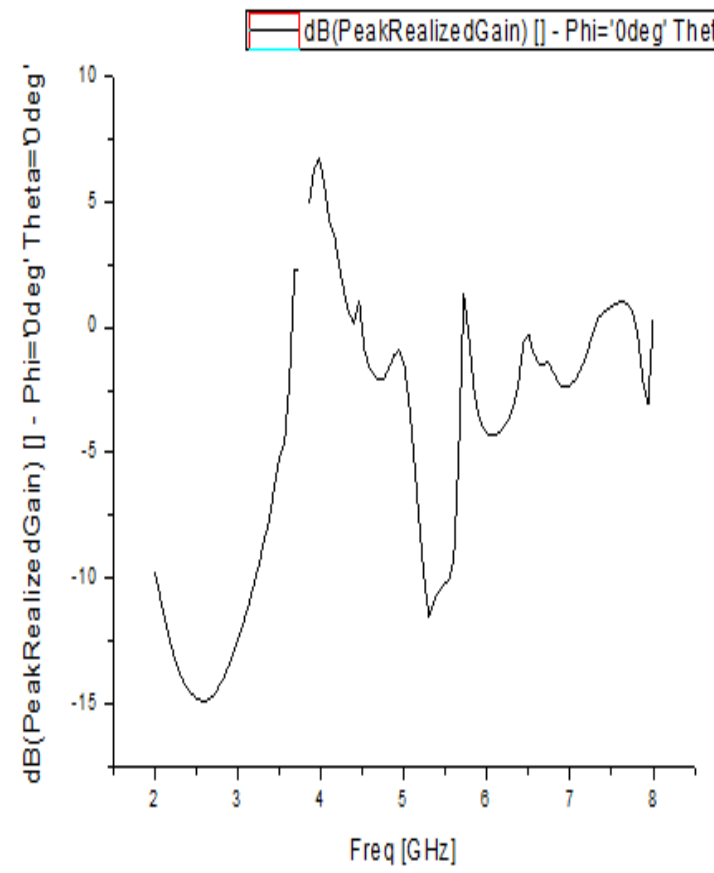

Fig. 4-Simulated Gain

Fig.6shows the measured radiation patterns admitting copolarization as well as cross-polarization in the $\mathrm{H}-$ plane $(\mathrm{x}-\mathrm{z}$ plane) and E- plane (y-z plane). The main purpose of the radiation patterns is to express that the antenna really radiates over a wide frequency band. It can be seen that the radiation patterns in $\mathrm{x}-\mathrm{z}$ plane are nearly Omni-directional for the frequencies. 


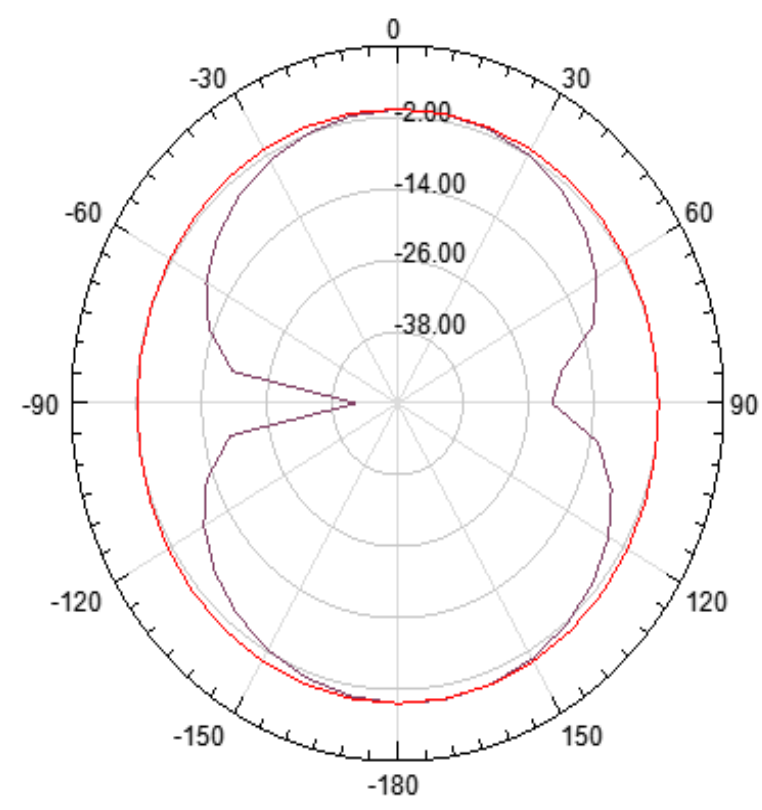

Fig. 5. Radiation pattern at frequency 5.6 GHz (H-E plane)

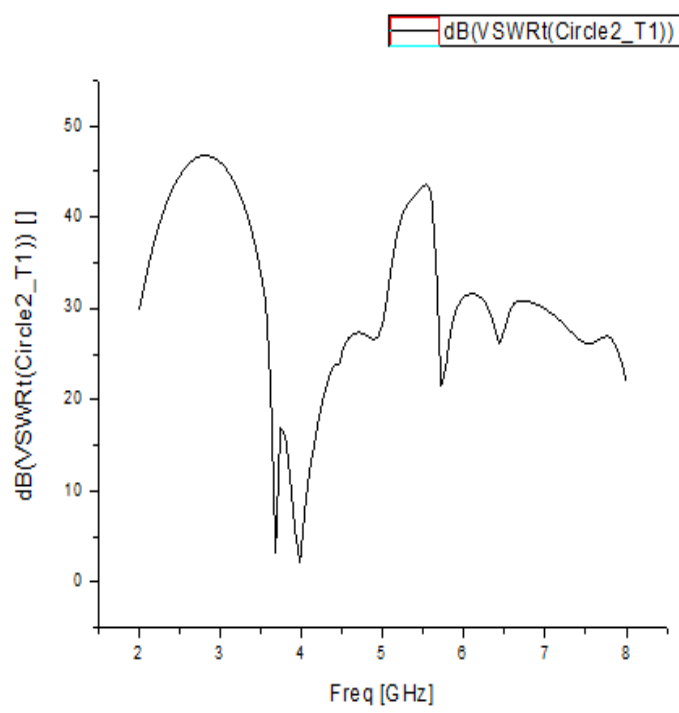

Fig. 6-VSWR

Table 1 shows the comparison between the different structure of the SMP antenna.

Table 1. Comparison of the results of the single and dual band SMP Antenna

\begin{tabular}{|l|l|l|l|l|}
\hline S.No. & Structure & $\begin{array}{l}\text { Resonant } \\
\text { Freq.(GHz) }\end{array}$ & $\begin{array}{l}\text { Return } \\
\text { Loss(dB) }\end{array}$ & $\begin{array}{l}\text { Gain } \\
\text { (dB) }\end{array}$ \\
\hline $\mathbf{1}$ & $\begin{array}{l}\text { Simple SMP } \\
\text { Patch }\end{array}$ & 2.335 & -17.9 & 0.915 \\
\hline $\mathbf{2}$ & $\begin{array}{l}\text { SMP Patch } \\
\text { with } \\
\end{array}$ & $3.79,6.4$ & -16.14, & $4.9,6.6$ \\
\hline $\mathbf{3}$ & Slit Cut & & -12.39 & \\
& Optimized & $3.68,3.98$ & -14.67, & 6 \\
& SMP & & -18.09 & \\
& Patch with & & & \\
& Slit & & & \\
\hline
\end{tabular}

\section{CONCLUSION}

Various structures of microstrip patch antenna have been analyzed and then antenna is simulated on An soft's HFSS v 13.First the simple patch have been studied and then using the same structure SMP patch was studied. After these analyses, simple silt is cut to achieve dual band with high gain. Results such as return loss, VSWR and radiation pattern were plotted in HFSS v 13 for various structures of antennas. The antenna possess dual band characteristics with resonating frequencies of bands at $3.68 \mathrm{GHz}$ and $3.98 \mathrm{GHz}$. slit cutting in patch. Therefore, overall gain of antenna was increased and it comes out to be $5.9 \mathrm{~dB}$ as compare to simple patch with $3.2 \mathrm{~dB}$ of gain. This Antenna is worth for multi operations such as communication satellite, weather radar, surface ship radar and wireless network equipment.

\section{REFERENCES}

[1] N. Ojaroudi, M. Ojaroudi, and N. Ghadimi,"Dual bandnotched small monopole antenna with novel W-shaped conductor backed-plane and novel T-shaped slot for UWB applications," IET Microwaves, Antennas \& Propagation,vol. 7, pp. 8-14, 2013.

[2] Bao, X.L., and Ammann, M.J.: 'Wideband dual-frequency dual polarized dipole-like antenna', IEEE Antennas Wirel. Propag. Lett., 2011,10, pp. 831-834

[3] C.Y. Hong, C.W. Ling, I.Y. Tarn, and S.J. Chung, "Design of a planar ultrawideband antenna with a new band-notch structure," IEEE Transactions on Antennas and Propagation, vol. 55, pp. 3391-3397, 2007.

[4] Y.J. Cho, K.H. Kim, D.H. Choi, S.S. Lee, and S.-O. Park, "A miniature UWB planar monopole antenna with 5-GHz band-rejection filter and the time-domain characteristics," IEEE Transactions on Antennas and Propagation, vol. 54, pp. 1453-1460, 2006.

[5] R. Karimian, H. Oraizi, S. Fakhte IET Microw. Antennas Propag., 2014, Vol. 8, Iss. 8, pp. 604-610 doi: 10.1049/ietmap.2013.0085

[6] Bing Gong, Xue Shi Ren, Ying Yin Zeng, Lin Hua Su, Qiu Rong Zheng," Compact slot antenna for ultra-wide band applications"IET Microw. Antennas Propag., 2014, Vol. 8, Iss. 3, pp. 200-205 doi: 10.1049/iet-map.2013.0067.

[7] M. Mehranpour, J. Nourinia, Ch. Ghobadi, and M. Ojaroudi,"Dual Band-Notched Square Monopole Antenna for Ultrawideband Applications"IEEE Antennas and Wireless Propagation Letters, VOL. 11, 2012.

[8] P.F.Hu, Y.M.Pan, X.Y.Zhang and S.Y.Zheng," A Compact Filtering Dielectric Resonator Antenna with wide bandwidth and high gain"AP1512-1940.R1,2016.

[9] Y.H. Zhao, J.P. Xu, and K.Yin, "Dual band-notched ultrawideband microstrip antenna using asymmetrical spurlines," Electronics Letters, vol. 44, pp. 1051-1052, 2008.

[10] W.-S. Chen, Y.-H. Yu, "Compact design of T-type monopole antenna with asymmetrical ground plane for WLAN/WiMAX applications," Microwave and Optical Technology Letters, vol. 50, pp. 515-519, 2008.

[11] R. Zaker, C. Ghobadi, and J. Nourinia, "Novel modifiedUWB planar monopole antenna with variable frequency band-notch function,'IEEEAntennas Wireless Propag. Lett., vol. 7, pp. 112-114, 2008. 